\title{
IGNEOUS ORIGIN FOR THE Na IN THE CLOUD OF IO
}

\author{
Mary L. Johnson and D. S. Burnett \\ Division of Geological and Planetary Sciences, California Institute of Technology
}

\begin{abstract}
We heated mixtures of sulfur and Na-bearing silicates in evacuated silica glass capsules to temperatures between $600^{\circ} \mathrm{C}$ and $950^{\circ} \mathrm{C}$. At or above $850^{\circ} \mathrm{C}, \mathrm{Na}$-silicate glass reacts with elemental $\mathrm{S}$ to form a $(\mathrm{Na}, \mathrm{K})$ sulfide. Mobilization of this phase may account for the presence of $\mathrm{Na}$ and $\mathrm{K}$ on the surface of Io, and hence in the material sputtered into the Jovian magnetosphere.
\end{abstract}

\section{Introduction}

The atomic $\mathrm{Na}$ cloud around Io has been studied for approximately 15 years, but although much is known about the temporal and spatial variations of the cloud, its origin remains enigmatic (Cheng et al., 1986; Nash et al., 1986). Surface sputtering is the consensus mechanism for supplying $\mathrm{Na}$ atoms to the cloud. Estimated $\mathrm{Na}$ loss rates are very uncertain, ranging from $1-10 \times 10^{26}$ atoms/sec, not greatly less than equivalent estimates for $S$ or $O$ which are in the $10^{27}-10^{29}$ atom/sec range (Cheng et al.). Despite the uncertainties, significant sources of $\mathrm{Na}$ on the surface of Io appear to be required.

We have performed simulation experiments to study the possibility that igneous interactions between elemental $\mathrm{S}$ and silicate materials have extracted $\mathrm{Na}$ from silicates and transported it to the surface along with elemental S.

\section{Experimental}

Sulfur and sodium-bearing silicates were loaded into vacuum-sealed silica glass capsules $(6 \mathrm{~mm}$ OD $\mathrm{x}$ $2 \mathrm{~mm}$ ID), using reagent sulfur, $99.95 \%$ pure. Silicates were Amelia albite or soda-lime glass (approx. composition 17.7 wt $\% \mathrm{Na}_{2} \mathrm{O}, 3.3 \% \mathrm{MgO}, 2.5 \% \mathrm{Al}_{2} \mathrm{O}_{3}, 69 \%$ $\mathrm{SiO}_{2}, 0.6 \% \mathrm{~K}_{2} \mathrm{O}, 5.9 \% \mathrm{CaO}, 0.9 \% \mathrm{TiO}_{2}$ ). Each capsule was loaded with $75 \pm 15 \mathrm{mg}$ sulfur and $1 \mathrm{~cm}$ long pieces of $0.7 \mathrm{~mm}$ diameter soda-lime glass rod, or $3-50 \mathrm{mg}$ of albite as $0.1-1 \mathrm{~mm}$ pieces. Charges were beld at temperatures between $600^{\circ}$ and $945^{\circ} \mathrm{C}$ for periods of 3 to 22 days. Presumably because of the high vapor pressure of $S$ at these temperatures (e.g. 35 atmospheres at $850^{\circ} \mathrm{C}$ ), there was a significant capsule failure rate above $800^{\circ} \mathrm{C}$. Charges were removed from the furnace and allowed to cool in air.

Copyright 1990 by the American Geophysical Union.

Paper number 90GL00748

$0094-8276 / 90 / 90 G L-00748 \$ 03.00$
Results

$\mathrm{X}$-ray analyses with a scanning electron microscope (SEM) yielded no significant concentrations of $\mathrm{Na}$ in yellow S. The best upper limit was set with a thin window $\mathrm{Si}(\mathrm{Li})$ detector, 0.2 weight $\%$ for a sample heated with soda-lime glass at $850^{\circ} \mathrm{C}$ for 14 days. This limit is consistent with limits on the solubility of elemental Na in S by Rosen and Tegman (1972) for an immiscible Na-rich sulfide melt coexisting with $S$ at temperatures up to $650^{\circ} \mathrm{C}$ (maximum $\mathrm{Na}$ content in molten sulfur of $0.3 \%$ ).

No reaction was noted between sulfur and silicates at 600,632 , or $750^{\circ} \mathrm{C}$; however, the higher temperature $\left(850^{\circ}\right.$ and $\left.900^{\circ} \mathrm{C}\right)$ runs with soda-lime glass contained a brown run product as well as silicate and yellow sulfur. The brown phase altered in contact with the air, first turning green and translucent, then turning clear (gel?). It also decomposed under a focused nA electron beam in the SEM. At these higher temperatures losses of $\mathrm{Na}$ (up to 12\%) and $\mathrm{K}$ (up to 50\%) in the soda-lime glass, relative to unheated glass, were observed in heated glass samples, along with rim to center depletions of $\mathrm{Na}$ (but not always for $\mathrm{K}$ ).

All high-temperature runs containing sulfur and soda-lime glass $\left(850^{\circ} \mathrm{C}\right.$ for $3,7,14$, and 18 days; $900^{\circ} \mathrm{C}$ for 8 days) developed the brown phase. No brown material was seen in two sulfur charges run for 7 days at $850^{\circ} \mathrm{C}$ which did not contain sodium silicates or in runs in which the $S$ was omitted. These experiments prove that the brown phase was formed by interaction of elemental $\mathrm{S}$ and soda-lime glass.

Brown or green material was observed: as flat crystals(?) occurring as films on both soda-lime and $\mathrm{SiO}_{2}$ glass surfaces (Figure 1), as complex swirls within the quenched sulfur, suggesting an immiscible melt phase, and as angular chunks or dark spots in yellow sulfur.

We believe that this brown material is alkali sulfide (or sulfides) for the following reasons:

1) X-ray spectra of 7 regions on fragments from the $900^{\circ} \mathrm{C}$ run chosen for their green color show $\mathrm{Na}, \mathrm{K}$, and $S X$-ray spectra in 5 cases. The other two show only $S$, probably due to a thin coating of yellow sulfur over the green phase. Spectra from the $850^{\circ} \mathrm{C}$ runs also show $\mathrm{Na}, \mathrm{K}$, and $\mathrm{S}$ in isolated regions of the samples.

2) The dark color of the brown-green phase resembles descriptions of sodium sulfides, especially beta $\mathrm{Na}_{2} \mathrm{~S}_{2}$ (see Oei, 1973; Rosen and Tegman, 1972; Pearson and Robinson, 1930); $\mathrm{Na}$ and $\mathrm{K}$ sulfites and sulfates are colorless. The dark color seen in our samples compared to colorless $\mathrm{Na}_{2} \mathrm{~S}$ may be due to the $\mathrm{K}$ present, as $\mathrm{K}$ sulfides are darker than $\mathrm{Na}$ sulfides (Feher and Berthold, 1953), or to trace amounts of $\mathrm{Ti}$ or $\mathrm{Fe}$ extracted from the soda-lime glass. The crystals shown 


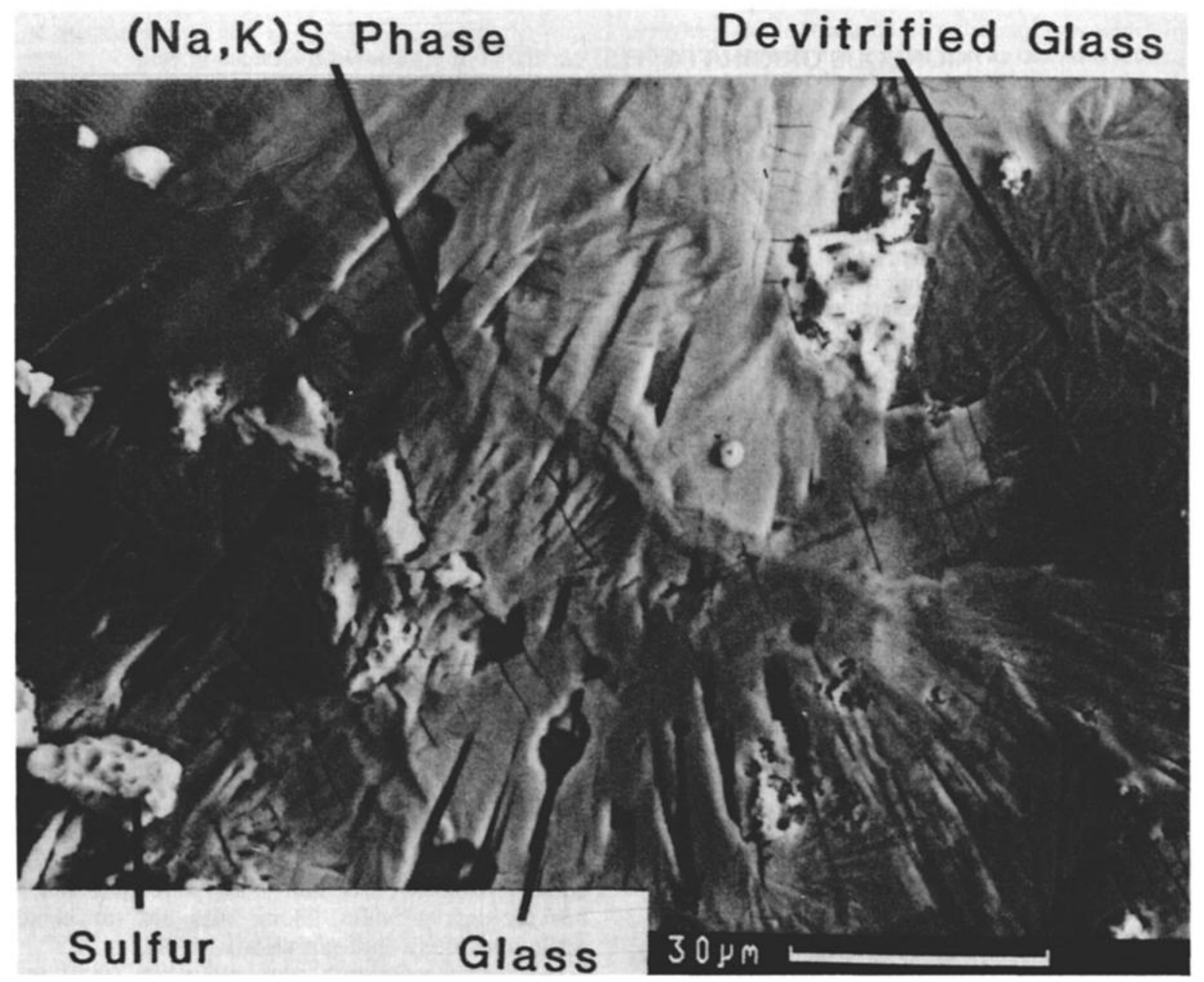

Fig. 1. SEM Back-scattered image of surface of soda-lime glass rod, $900^{\circ} \mathrm{C}$ run, showing sulfur (bright, porous), alkali sulfide phase (light gray flat prisms covering most of image; some crystals are cracked transverse to their length), and devitrified glass (dark gray, right hand side). The radiating needles on the glass surface are $\mathrm{CaMgSi}_{2} \mathrm{O}_{6}$. in Figure 1 resemble those of $\mathrm{Na}_{2} \mathrm{~S}_{2}$ in Plate 1 of Pearson and Robinson (1930).

3) Semi-quantitative analyses of the $X$-ray spectra of six regions from the $900^{\circ} \mathrm{C}$ run give a $1: 1(\mathrm{Na}+\mathrm{K}): \mathrm{S}$ ratio in four cases (Figure 2). These analyses are uncertain because they are not made on flat polished samples as is required for quantitative $\mathrm{X}$-ray microanalysis; however, an attempt was made visually to orient the analyzed areas into flat-lying geometry. Some of the samples were rotated by +5 degrees with no noticeable changes in the $X$-ray spectra. The clustering of the alkali to sulfur ratio around 1 appears to be significant and rules out sulfates or sulfites for which the alkali to sulfur ratio would be 2 .

There are complications in the data presented on Figure 2. It is likely that air exposure has partially oxidized/hydrated the green materials analyzed. This may lead to alkali sulfate formation which may explain the point with alkali/S about 2 . Alternatively, both $(\mathrm{Na}, \mathrm{K})_{2} \mathrm{~S}$ and $(\mathrm{Na}, \mathrm{K})_{2} \mathrm{~S}_{2}$ may be present. We also cannot rule out the possibility that small amounts of sulfite or sulfate are present which, being colorless,

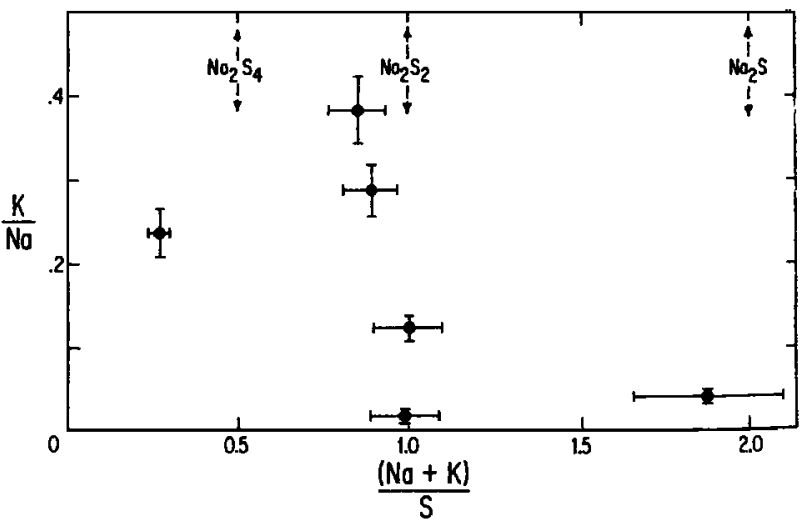

Fig. 2. Semi-quantitative analyses of alkali sulfide phase (ZAF correction; Amelia albite $\mathrm{Na}$ standard, Asbestos microcline $\mathrm{K}$ standard; anhydrite $\mathrm{S}$ standard). Four points show $\mathrm{Na}_{2} \mathrm{~S}_{2}$ stoichiometry, and one is consistent with $\mathrm{Na}_{2} \mathrm{~S}$. Note variable $\mathrm{K}$ to $\mathrm{Na}$ ratio. 
would be easy to miss in the presence of a large amount of yellow-white S. The point on Figure 2 with low alkali/S can be explained by an admixture of $S$ in the 5-10 micron beam spot as the sulfide and $S$ are intimately mixed. The possibility that all analyses represent mixtures of $(\mathrm{Na}, \mathrm{K})_{2} \mathrm{~S}$ and $\mathrm{S}$ cannot be completely ruled out, but the clustering of such analyses near alkali/S=1 would not be expected. The variable $\mathrm{K} / \mathrm{Na}$ probably reflects lack of equilibrium associated with only partial reaction of $S$ and silicate.

Albite runs at 850 and $950^{\circ} \mathrm{C}$ did not contain brown-green material, and no Na-sulfur compounds have been found. The albite showed evidence of reaction, being essentially destroyed in the $950^{\circ} \mathrm{C}$ run; but this very likely reflects reaction with the $\mathrm{SiO}_{2}$ glass container. These samples had extensive air exposure before the significance of dark-colored material was appreciated, thus there is a remote possibility that sulfides were present but have reacted. Alternately, sulfides may not be dark-colored if $\mathrm{K}, \mathrm{Ti}$, or other elements from the soda-lime glass are important coloring agents.

\section{Discussion}

We have shown that, while the solubility of $\mathrm{Na}$ in sulfur is probably not significant, elemental sulfur will react with silicate glass to produce alkali sulfides. It is quite plausible that analogous igneous processes could occur on Io and that alkali sulfides are a natural consequence of igneous activity on a S-rich planet. Alkali sulfides suspended in elemental $\mathbf{S}$ flows or erupted could be the source of the $\mathrm{Na}$ (and $\mathrm{K}$ ) observed around Io. The phase we have formed, $(\mathrm{Na}, \mathrm{K})_{2} \mathrm{~S}_{2}$, is presumably that favored by the kinetics of our experiments and need not be the actual compound formed on Io.

The absence of $\mathrm{Si}$ in the inner magnetosphere ion mass distributions (e.g. Krimigis and Rolef, 1983; Vogt et al., 1979) is a strong argument that direct sputtering of silicate materials cannot account for the atomic $\mathrm{Na}$ cloud; however there are indirect means, e.g. volcanic outgassing of alkalis followed by sputtering, that can preferentially derive the $\mathrm{Na}$ from silicates (compare Hapke, 1989).

The reflectance spectra for lo are compatible with large amounts of $\mathrm{Na}_{2} \mathrm{~S}$ (see e.g. Nash et al., 1986; Clark et al., 1986; Nash, 1988). Thus, several studies have proposed $\mathrm{Na}_{2} \mathrm{~S}$ as the $\mathrm{Na}$ compound on the surface of Io (see e.g. Fanale et al., 1982, Nash et al., 1986, Chrisey et al., 1988) but relatively little discussion has been given of how $\mathrm{Na}_{2} \mathrm{~S}$ might form. $\mathrm{Na}_{2} \mathrm{~S}$ is not found terrestrially or in meteorites, although $(\mathrm{Na}, \mathrm{Fe}),(\mathrm{Na}, \mathrm{Cr})$ and K-sulfides are known. VanHecke and Nash (1984) and Lunine and Stevenson (1985) propose that the interaction of elemental S and silicates would form Na-sulfides. VanHecke and Nash (1984) base their conclusion on thermodynamic calculations for $\mathrm{Na}_{2} \mathrm{~S}$ formation by reaction of $\mathrm{S}$ with $\mathrm{Na}$ ortho- or metasilicates. One could quibble about the relevance of these specific reactions, but our experiments demonstrate the plausibility of their basic suggestion. Because of the relatively low sputtering yield of $\mathrm{Na}_{2} \mathrm{~S}$, Chrisey et al. speculate that polysulfides are dominant.
Based on terrestrial and meteoritic experience, it is not intuitive that sodium should form sulfides rather than silicates or oxides under igneous conditions. However, alkali sulfides are thermodynamically stable, as discussed by Lewis (1971). For example the reaction $2 \mathrm{Na}_{2} \mathrm{O}+3 \mathrm{~S} \rightarrow 2 \mathrm{Na}_{2} \mathrm{~S}+\mathrm{SO}_{2}$

is favorable thermodynamically at igneous temperatures (compare VanHecke and Nash), although the equivalent reaction with albite is not favorable, consistent with our observations. Lewis also noted that $\mathrm{K}$ sulfides are more stable than Na sulfides, and, indeed, $\mathrm{K}$ partitions more strongly than $\mathrm{Na}$ into the sulfide phase in our experiments.

Reaction of volcanic glass on Io with sulfur could provide a mechanism for forming $\mathrm{SO}_{2}$ along with sulfides. The data on Io-derived material in the Jovian magnetosphere suggests that there is much more $\mathrm{SO}_{2}$ than $\mathrm{Na}$ on the Io surface, but quantitative estimates are highly uncertain, and given the ease by which surficial deposits would be preferentially observed and sputtered, the importance of $\mathrm{SO}_{2}$ relative to more reduced $S$ compounds could be less than has been generally believed.

As noted, there is little terrestrial or meteoritic evidence for the theoretical stability of alkali sulfides. In the equilibrated enstatite (E6) chondrites, which are the best approximation to an equilibrium assemblage under very low oxygen fugacity (which favors sulfide formation), $\mathrm{Na}$ and $\mathrm{K}$ are found in feldspar, although other lithophile elements such as $\mathrm{Ca}, \mathrm{Ti}, \mathrm{Mn}, \mathrm{U}$, and $\mathrm{Th}$ are found in sulfides (Furst et al., 1981). Similarly, Murrell and Burnett (1986) found little partitioning of $\mathrm{K}$ from a silicate to an $\mathrm{Fe} / \mathrm{FeS}$ liquid. Given these observations, our success in producing alkali sulfides may be due to the high $\mathrm{S}_{2}$ fugacity in our experiments rather than low $\mathrm{O}_{2}$ fugacity associated with enstatite chondrites.

Silicate melts continually invading the crust of Io (e.g. Kieffer, 1982, Lunine and Stevenson, 1985) provide high temperatures for reaction and a source of $\mathrm{Na}$. Because a high sulfur fugacity appears necessary to form $\mathrm{Na}$-sulfides, the existence of the Io $\mathrm{Na}$ cloud itself may be a strong argument for free sulfur on Io, as there is little direct evidence for elemental S (see e.g. Clark et al., 1986, Hapke, 1989). A complication to this interpretation is the possibility that direct reaction of $\mathrm{SO}_{2}$ with silicates might form Na-sulfur compounds (VanHecke and Nash), independent of the presence of elemental S.

The origin of elemental S on Io is a major issue. CI chondrites contain a few percent free sulfur, lesser amounts bound up in hydrocarbons, and free sulfides. There are large amounts of $S$ as free sulfates or sulfide in layer-lattice silicates (DuFresne and Anders, 1962; McSween, 1979). Thus, a CI source model for Io automatically delivers elemental and oxidized $\mathrm{S}$ (compare Lewis, 1982); however, the effect of planetary accretion on this disequilibrium assemblage is unclear.

Given elemental S and volcanic activity, neither evaporite deposits nor an aqueous/icy prehistory for Io, as suggested by Fanale et al. (1977), are required to explain the atomic $\mathrm{Na}$ cloud, although a literal CI-analog parent material would have to lose a lot of water. Perhaps the water could have been lost in the proto-Jovian nebula before Io accreted. 
Although more experiments are required to explore the generality of our results and, especially, to define the role of oxygen fugacity and effects of the presence of other elements such as $\mathrm{Ca}$ or $\mathrm{Fe}$, we propose that an igneous origin for the $\mathrm{Na}$ observed and in the Jovian magnetosphere should be seriously considered.

\section{Acknowledgments}

We thank Jeffery Warner (Chevron Research Lab) for aid in SEM analysis and John Pirolo and Gabor Faludi for glass working. Mary Johnson thanks Mark Parisi, as usual. This research was supported by NASA NAGW-1741.

\section{References}

Cheng, A. F., P. K. Haff, R. E. Johnson, and L. J. Lanzerotti, Interaction of planetary magnetospheres with icy satellite surfaces, in Satellites,(J. A.Burns and M. S. Matthews, Eds.) pp. 403-436, U. Ariz. Press, Tucson, 1986.

Chrisey, D. B., R. E. Johnson, J. W. Boring, and J. A. Phipps, Ejection of sodium from sodium sulfide by the sputtering of the surface of Io, Icarus 75 , 233-2449, 1988.

Clark, R. N., F. P. Fanale, and M. J. Gaffney, Surface composition of natural satellites, in Satellites_(J. A. Burns and M. S. Matthews, Eds.) pp. 437-491, U. Ariz. Press, Tucson, 1986.

DuFresne, E. R., and E. Anders, On the chemical evolution of the carbonaceous chondrites, Geoch. et Cosmoch. Acta 26, 1085-1114, 1962.

Fanale, F. P., W. B. Banerdt, L. S. Elson, T. V. Johnson, and R. W Zurek, Io's surface: its phase composition and influence on Io's atmosphere and Jupiter's magnetosphere, in Satellites of Jupiter (D. Morrison, Ed.), pp. 756-781, U. Ariz. Press, Tucson, 1982.

Fanale, F. P., T. V. Johnson, and D. L. Matson, Io's surface composition: observational constraints and theoretical considerations, Geophys. Res. Lett. 4, 303-306, 1977.

Feher, F., and H.J. Berthold, Uber das System Kalium-Schwefel, Zeit. Anorg. Allgem. Chem. 274, 223-233, 1953.

Furst, M. J., M. I. Stapanian, and D. S. Burnett, Observation of non-lithophile behavior for U, Geophys. Res. Lett. 9,41-44, 1982.

Hapke, B., The surface of Io: a new model, Icarus 79, 56-74, 1989.

Kieffer, S. W., Dynamics and thermodynamics of eruptions: implications for the plumes of Io, in
Satellites of Jupiter (D. Morrison, Ed.), pp. 647-723, U. Ariz. Press, Tucson, 1982.

Krimigis, S. M. and E. C. Roelof, Low energy particle population, in Physics of the Jovian Magnetosphere (A. J. Dessler, Ed.), pp. 106-156, Cambridge Univ. Press, Cambridge, 1983.

Lewis, J. S., Consequences of the presence of sulfur in the core of the earth, Earth Planet. Lett. 11, 130-134, 1971.

Lewis, J.S., Io: geochemistry of sulfur, Icarus, 50, 103-114, 1982

Lunine, J. I., and D. J. Stevenson, Physics and chemistry of sulfur lakes on Io, Icarus $64,345-367$, 1985.

McSween, H.Y., Are carbonaceous chondrites primitive or processed? A review, Rev. Geophys., Space Phys., 17, 1059-1078, 1979.

Murrell, M. T., and D. S. Burnett, Partitioning of $\mathrm{K}$, $U$, and Th between sulfide and silicate liquids: implications for heating of planetary cores, J. Geophys. Res. 91, B8126-B8136, 1986.

Nash, D. B., Infrared reflectance spectra of $\mathrm{Na}_{2} \mathrm{~S}$ with contaminant $\mathrm{Na}_{2} \mathrm{CO}_{3}$ : effects of adsorbed $\mathrm{H}_{2} \mathrm{O}$ and $\mathrm{CO}_{2}$ and relation to studies of Io. Icanus 74, 365-368, 1988.

Nash, D. B., M. H. Carr, J. Gradie, D. M. Hunten, and C. F. Yoder, Io, in Satellites (J. A. Burns and M. S. Matthews, Eds.), pp. 629-688, U. Ariz. Press, Tucson, 1986.

Oei, D., The sodium-sulfur system. I. Differential thermal analysis, Inorg. Chem. 12, 435-437, 1973.

Pearson, T. G., and P. L. Robinson, The polysulphides of the alkali metals, Part I. Sodium (i). J.' Chem. Soc. XX, 1473-1497, 1930.

Rosen, S. J., and R. Tegman, Solid, liquid, and gas phase equilibria in the system sodium monosulfide-sodium polysulfide-sulfur, Chemica Scripta 2, 221-225, 1972.

VanHecke, G.R., and Nash, D.B., On the S-O-Na chemistry and recycling of Io's surface, unpublished manuscript, 1984.

Vogt, R.E., W.R. Cook, A.C. Cummings, T.L. Garrard, N. Gehrels et al., Voyager 1: Energetic ions and electrons in the Jovian magnetosphere. Science 204, 1003-1007, 1979.

M.L. Johnson and D.S. Burnett, Dept. of Geological and Planetary Sciences, California Institute of Technology, Pasadena, CA 91125.

(Received December 29, 1989;

revised March 6, 1990; accepted March 9, 1990.) 